\title{
Preparation and characterization of cefuroxime axetil solid dispersions using poloxamer 188
}

\author{
Thaeer Sankari ${ }^{1 *}$, Sahar Al-Hariri ${ }^{1}$ \\ ${ }^{1}$ Department of Chemistry, Faculty of Science, Damascus University, Damascus, Syria
}

\begin{abstract}
The main objective of the present work was to enhance the solubility and dissolution rate of poorly water-soluble drug cefuroxime axetil (CA) by formulating it into solid dispersions (SDs) with water soluble carrier poloxamer 188. Different methods were employed to prepare the dispersion, such as: Solvent method (SM), Kneading method (KM), Melt evaporation method (MEM) and Physical mixture (PM) in different drug: carrier ratios 1:1, 1:2 and 1:3 (cefuroxime axetil: poloxamer 188). The physical mixture(s) and solid dispersion(s) were characterized for drug carrier interaction, drug content, solubility, dissolution rate, differential scanning calorimetry (DSC) and FT-IR study. The dissolution rate of the prepared solid dispersion systems was determined in phosphate buffer ( $\mathrm{pH}$ 6.8) for $1 \mathrm{~h}$. The solubility of drug from different systems was also determined in water. All SD formulations were found to have a higher dissolution rate comparatively to pure CA. The dissolution rate was enhanced in the following order $\mathrm{SM}>\mathrm{MEM}>\mathrm{KM}$. The enhancement of dissolution rate may be caused by increase wettability, dispersibillity reduction in particle size or the formation of CA $\beta$ crystalline. The FT-IR study probability revealed that there was no chemical interaction between drug and poloxamer 188 .
\end{abstract}

Keywords: Cefuroxime axetil/dissolution. Poloxamer 188. Solid dispersion.

\section{INTRODUCTION}

Over the last years, the number of poorly soluble drugs has significantly increased. Poorly watersoluble drugs show unpredictable absorption, since their bioavailability depends upon dissolution in the gastrointestinal tract (Gorajana et al., 2015). Dissolution provides valuable information about bioavailability of the drug. It is considered to be one of the most important quality control tests performed on pharmaceutical dosage form (Razvi, Siddiqui, Khan, 2005). The important phenomenon in pharmaceutical formulation is "solubility" which plays very effective and significant role in the formulation of various dosage forms (Reddy et al., 2013). Aqueous solubility of a drug can be a critical limitation to its oral absorption. Poorly water-soluble drugs are associated with slow drug absorption leading eventually to inadequate and variable bioavailability. The enhancement of oral bioavailability of poorly water-soluble drugs remains one of the most challenging aspects of drug

\footnotetext{
*Correspondence: T. Sankari. Department of Chemistry, Faculty of Science, Damascus University, Qudssaya Suburb, Damascus, Syria. Tel.: +963 (0)933073047. E-mail address: sankari.chem@gmail.com (Th. Sankari)
}

development (Prasanthi et al., 2011). Various techniques have been used to improve the solubility/dissolution rate of poorly water-soluble drugs (Jithendra et al., 2013). Solid dispersions have been widely used to enhance the solubility, dissolution rate, and bioavailability of poorly soluble drugs, there are different types of solid dispersion systems categorized according to the physical states of the drug and the carrier in the systems (Liu et al., 2006). Solid dispersion (SD) refers to a group of solid products consisting of at least two different components, generally a hydrophilic matrix and a hydrophobic drug. The matrix can be either crystalline or amorphous. The drug can be dispersed molecularly, in amorphous particles or in crystalline particles (Nokhodchi et al., 2007). In other words, SD involved a dispersion of one or more active ingredients in an inner carrier in solid state (Chaulang et al., 2008). Poloxamer block copolymers have been exploited in pharmaceutical formulations for solubilization of poorly water-soluble drugs. Poloxamers consist of an ethylene oxide hydrophilic core and polypropylene oxide hydrophobic core blocks arranged in a tri block structure resulting in an amphiphilic structure. Owing to their low melting point, they are suitable for the melt technique in solid dispersions. Their ability to self aggregate, thereby 
forming micelles and liquid crystalline phases and greater hydrophilicity is another advantage for the solubilization of poorly water-soluble drugs. For drug delivery purposes, hydrophobic drugs may be solubilized within the core of the micelle or conjugated to the micelle forming polymer. These amphiphilic co-polymers are available in different grades as poloxamer 188 and poloxamer 407 (EI-Badry et al., 2013). Poloxamer 188 was used to enhance the dissolution rate of several drugs such as cefuroxime axetil, sulfadiazine, sulfisoxazole, sodium diclofenac and midazolam (Sruti et al., 2013; Reddy, Khalil, Gouda 1976; Datta, Kaur, 2014; Jithendra et al., 2013). Cefuroxime (CA), a semi-synthetic broad-spectrum 2nd generation cephalosporin, is among one of the antibiotics widely used to treat bacterial infections (Dellamonica, 1994). Besides treating lower respiratory tract infections, CA may also be used to treat upper respiratory tract infections, skin and soft tissue infections, and genitourinary tract infections caused by susceptible bacteria. It may also be employed for prophylaxis purposes in conditions such as coronary artery bypass grafting surgery or elective cholecystectomy (Pichichero, 2007). Cefuroxime axetil, Chemically, 1-acetoxyethyl (6R,7R)-3-[(carbamoyloxy) methyl]-7-\{[(2Z)-2-(2-furyl)-2-(methoxyimino)acetyl] amino -8-oxo-5-thia-1-azabicyclo[4.2.0]oct-2-ene-2carboxylate (See Figure 1), is an oral prodrug of the bactericidal cephalosporin antibiotic cefuroxime, which is resistant to degradation by most $\beta$-lactamases and is active against a wide range of Gram-positive and Gramnegative organisms. It is used frequently for pediatric conditions like upper respiratory tract infections (Vinod, Chenthilnathan, 2013). Cefuroxime axetil is slightly soluble in water (British Phamacopoeia, 2009), and its poor aqueous solubility and wettability gives rise to difficulties in pharmaceutical formulations for oral and parenteral delivery. The aim of the present investigation was to enhance the solubility, dissolution rate of CA with solid dispersion technique using Poloxamer 188 as a hydrophilic carrier, and evaluated the effect of it on

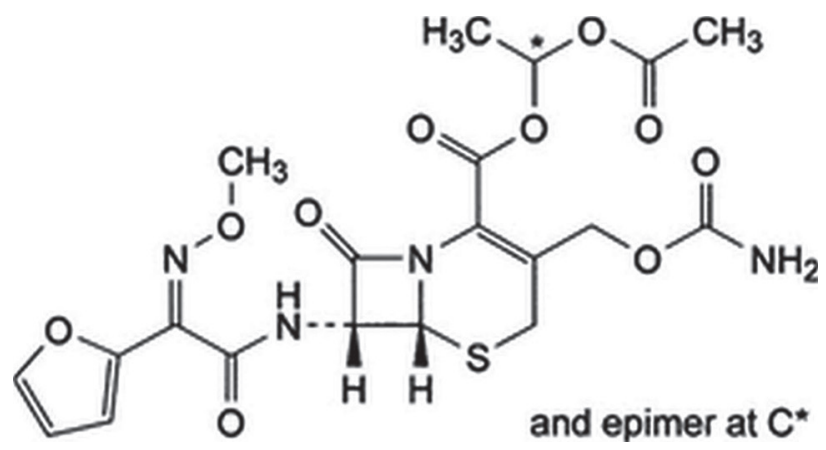

FIGURE 1 - Structural formula of cefuroxime axetil. solubility profile of the drug. Solid dispersion systems of the drug with Poloxamer 188 were prepared in different ratios by solvent, kneading and melt evaporation techniques. The physicochemical properties of the prepared solid dispersion were evaluated using different methods.

\section{MATERIAL AND METHODS}

\section{Materials}

Pure cefuroxime axetil (CA) and poloxamer 188 were obtained as gratis sample from DIAMOND PHARMA, Syria. Sodium dihydrogen phosphate and Disodium hydrogen phosphate of AR grade and other chemicals of AR grade were purchased from E. Merck ${ }^{\circledR}$ (Germany).

\section{Preparation of CA solid dispersions (SDs) using different techniques}

Different drug: polymer ratios (1:1, 1:2 and 1:3) (Table I) were used for preparing CA solid dispersions in Poloxamer 188 matrix, via melt evaporation method (MEM), solvent method (SM) and kneading method (KM).

TABLE I - Drug-carrier weight ratio in prepared formulations. $\mathrm{CA}$ is pure cefuroxime axetil, $\mathrm{S}_{1}$ to $\mathrm{S}_{3}$ are solid dispersions (SM), $\mathrm{K}_{1}$ to $\mathrm{K}_{3}$ are solid dispersions (KM), $\mathrm{M}_{1}$ to $\mathrm{M}_{3}$ are solid dispersions (MEM) and $\mathrm{P}_{1}$ to $\mathrm{P}_{3}$ are physical mixtures

\begin{tabular}{cc}
\hline Formulation code & Drug: Carrier ratio \\
\hline $\mathrm{CA}$ & $1: 0$ \\
$\mathrm{~S}_{1}$ & $1: 1$ \\
$\mathrm{~S}_{2}$ & $1: 2$ \\
$\mathrm{~S}_{3}$ & $1: 3$ \\
$\mathrm{~K}_{1}$ & $1: 1$ \\
$\mathrm{~K}_{2}$ & $1: 2$ \\
$\mathrm{~K}_{3}$ & $1: 3$ \\
$\mathrm{M}_{1}$ & $1: 1$ \\
$\mathrm{M}_{2}$ & $1: 2$ \\
$\mathrm{M}_{3}$ & $1: 3$ \\
$\mathrm{P}_{1}$ & $1: 1$ \\
$\mathrm{P}_{2}$ & $1: 2$ \\
$\mathrm{P}_{3}$ & $1: 3$ \\
\hline
\end{tabular}

\section{Solvent method (SM)}

In this method, the weighed amounts of CA and polymer dissolved in a minimum amount of methanol. 
Then, the organic solvents were removed by evaporation at room temperature. The dried mass was taken, pulverized and sieved. The samples were kept in desiccators until the experiment (EI-Badry et al., 2013).

\section{Kneading method (KM)}

In this method, the weighed amounts of CA and polymer kneaded with appropriate amounts of methanol using a mortar and pestle for $10 \mathrm{~min}$. The mass was dried (room temperature overnight), crushed, sieved and dried again in an oven at $40^{\circ} \mathrm{C}$ for $24 \mathrm{~h}$ (EI-Badry et al., 2013).

\section{Melt evaporation method (MEM)}

In this method accurately weighed of $\mathrm{CA}$ is dissolved in a minimum amount of methanol. The solution is incorporated into the melt of polymer. Then, the organic solvents were removed by evaporation until a clear, solvent free film is left. The film is further dried to constant weight and mass is kept in desiccators until the experiment.

\section{Preparation of physical mixture}

The physical mixtures were prepared by weighing cefuroxime axetil and poloxamer 188 and mixing them. The formulations were obtained by mixing the components using spatula in a mortar for 5 minutes. They were passed through 50-mesh sieve and kept in desiccators until the experiment.

\section{CHARACTERIZATION OF SOLID DISPERSIONS}

\section{Drug content}

A fixed amount of pure CA (150.3 mg) and CA SDs equivalent to $150.3 \mathrm{mg}$ of pure $\mathrm{CA}$ were weighed and dissolved homogenously with methanol. The solution was suitably diluted and the absorbance was measured at 280 $\mathrm{nm}$. Drug content was calculated using the appropriate equation.

\section{In-vitro dissolution rate testing}

Pure CA, CA SDs, and CA physical mixtures equivalent to $150.3 \mathrm{mg}$ of pure $\mathrm{CA}$ were tested for their dissolution profile individually in dissolution vessels for a period of $1 \mathrm{~h}$ in $900 \mathrm{~mL}$ phosphate buffer $\mathrm{pH} 6.8$ maintained at $37 \pm 0.5^{\circ} \mathrm{C}$ under $50 \mathrm{rpm}$ stirring rate (Pharma test DT
70, Germany). During this period, $10 \mathrm{~mL}$ of samples were withdrawn at regular intervals of time and analyzed using Ultraviolet-Vis spectrophotometer (UV- SHIMADZU $1800)$ at $280 \mathrm{~nm}$. The amount of drug released was calculated using the appropriate equation.

\section{Solubility studies}

A fixed amount of pure CA (150.3 mg) and CA SDs equivalent to $150.3 \mathrm{mg}$ of pure CA were weighed. These weighed samples were sealed tightly and mix with distilled water using an ultrasonicator at $40{ }^{\circ} \mathrm{C}$ for $1 \mathrm{~h}$. Following that, these conical tubes were removed and transferred into a shaking incubator, which was set to operate at $37^{\circ} \mathrm{C}, 100$ rpm for $24 \mathrm{~h}$. After $24 \mathrm{~h}$, the shaker was switched off while the conical tubes were left in the incubator for another 12 $\mathrm{h}$, incubating at $37^{\circ} \mathrm{C}$. The absorbance values for each sample were measured at $280 \mathrm{~nm}$, in duplicate (Gorajana et al., 2015).

\section{ATR- FTIR spectroscopy}

(ATR-FTIR) spectroscopy is used to assess the interaction between carrier or complexing agent and guest molecule in solid state. ATR-FTIR studies: Spectra for pure CA, Poloxamer 188 and solid dispersions were recorded in a FT-IR (BRUKER- TENSOR 27) spectrophotometer.

\section{Preparation of standard curve}

$50 \mathrm{mg}$ of drug was dissolved in $100 \mathrm{~mL}$ methanol to produce $500 \mu \mathrm{g} / \mathrm{mL}$ stock solution. From the stock solution, $0.5 \mathrm{~mL}$ is pipette out in to $100 \mathrm{~mL}$ volumetric flask and made up to the volume with phosphate buffer ( $\mathrm{pH}$ 6.8). Further dilutions were made to produce different concentrations from $2.5-20 \mu \mathrm{g} / \mathrm{mL}$. Standard solutions were then analyzed by Ultraviolet-Vis spectrophotometer (UV- SHIMADZU 1800) at $280 \mathrm{~nm}$ and absorbance was noted. Then the absorbance values were plotted against drug concentration and standard curve of cefuroxime axetil was produced.

\section{Differential scanning calorimetry (DSC) analysis}

Calorimetric studies of the drug and the prepared solid dispersion systems were performed using a DSC-20 (METTLER TOLEDO, Switzerland). All accurately weighed samples were placed in sealed aluminium pans before heating under nitrogen flow $(100 \mathrm{~mL} / \mathrm{min})$ at a scanning rate of $10^{\circ} / \mathrm{min}$ from 25 to $300^{\circ}$. 


\section{Kinetic analysis of drug release}

The dissolution profiles of all the SDs were subjected to the kinetic analysis to establish the drugrelease mechanism. The release data were fitted to zero order (equation 1), first order (equation 2) and matrix (Higuchi model) (equation 3 ) to ascertain the kinetic modeling of drug release (Gorajana et al., 2015).

$$
\begin{gathered}
\mathrm{Q}_{\mathrm{t}}=\mathrm{k}_{0} \mathrm{t} \\
\text { In } \mathrm{Q}_{\mathrm{t}}=\operatorname{In} \mathrm{Q}_{0}-\mathrm{k}_{1} \mathrm{t} \\
\mathrm{Q}_{\mathrm{t}}=\mathrm{k}_{\mathrm{H}} \mathrm{t}^{1 / 2}
\end{gathered}
$$

\section{Micromeritic properties of powder blends}

Micromeritic properties i.e. bulk density ( $\rho b)$, tapped density ( $\rho t)$, compressibility index (CI) and Hausner ratio (HR) of the blended powder were determined by the following formulas under BP2009 guidelines.

$\rho b=M$ (weight of the powder blend) / $\mathrm{Vb}$ (bulk volume) (1)

$\rho t=M$ (weight of the powder blend) / Vt (tapped volume) (2)

$\mathrm{CI}=(\rho \mathrm{t}-\rho \mathrm{b}) / \rho \mathrm{t} \times 100$

$\mathrm{HR}=\rho \mathrm{t} / \rho \mathrm{b}$

\section{RESULT AND DISCUSSION}

\section{In vitro dissolution studies}

The dissolution profiles of CA-Poloxamer- 188 solid dispersions (SDs) prepared using different methods for
CA were compared to those of the PM and drug itself. The dissolution study showed that the release percentage of pure CA after one hour was only $37.8 \%$ (Table II). During dissolution studies, it was noted that drug carrier systems sink immediately, whereas pure drug keeps floating on the surface for a longer time interval. There was an appeal difference between the release rate of pure CA and solid dispersions. Comparative dissolution profile showed that an increase in the percentage of Poloxamer 188 resulted in an increase in the release rate of CA. All the prepared SD systems showed a remarked enhancement of the in-vitro drug dissolution rate. In particular, SD systems prepared by Solvent method in ratio 1:3 was able to produce $79.59 \%$ of the drug in solution, while the melt evaporation method produce about $73.06 \%$ and the Kneading method produce about $66.94 \%$ of the drug in solution within one hour. On the other hand, the PM produced about $38.37 \%$ of the drug in solution. It could be seen that, Poloxamer- 188 has effectively enhanced the drug dissolution and this effect depended on the ratio of the carrier used and the method of the preparation of solid dispersion. (Figure 6) showed the comparison between the dissolution behavior of the drug from all different systems. It has shown that the Solvent method had the priority of the enhancing of the dissolution rate. It is evident that, in all solid dispersion preparation methods, increasing the Poloxamer-188 weight ratio was followed by increasing the amount of $\mathrm{CA}$ dissolved. The enhancement of dissolution of CA from solid dispersion systems may be due to lack of crystallinitty, amorphization, increase wettability and

\begin{tabular}{|c|c|c|c|c|c|c|c|c|c|}
\hline & \multicolumn{8}{|c|}{ Time (min) } \\
\hline & & 5 & 10 & 15 & 25 & 30 & 40 & $\mathbf{5 0}$ & 60 \\
\hline \multirow{13}{*}{ 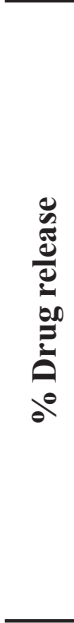 } & $\mathbf{C A}$ & $27.4 \pm 0.60$ & $28.6 \pm 0.96$ & $29.8 \pm 0.54$ & $35.0 \pm 0.59$ & $36.5 \pm 0.84$ & $36.8 \pm 1.09$ & $37.2 \pm 0.53$ & $37.8 \pm 0.90$ \\
\hline & $\mathrm{S}_{1}$ & $26.7 \pm 0.50$ & $37.8 \pm 0.57$ & $38.8 \pm 0.85$ & $42.7 \pm 0.44$ & $44.1 \pm 0.86$ & $49.0 \pm 0.60$ & $49.8 \pm 0.59$ & $48.0 \pm 0.40$ \\
\hline & $\mathrm{S}_{2}$ & $37.4 \pm 0.64$ & $41.8 \pm 0.74$ & $45.3 \pm 0.69$ & $47.0 \pm 0.36$ & $53.3 \pm 0.38$ & $53.1 \pm 0.50$ & $54.3 \pm 0.38$ & $52.7 \pm 0.80$ \\
\hline & $\mathrm{S}_{3}$ & $73.3 \pm 0.99$ & $76.5 \pm 0.72$ & $77.2 \pm 0.60$ & $78.6 \pm 1.00$ & $79.6 \pm 1.02$ & $78.0 \pm 0.40$ & $76.1 \pm 0.64$ & $75.5 \pm 0.50$ \\
\hline & $\mathbf{M}_{1}$ & $16.3 \pm 0.40$ & $15.5 \pm 0.85$ & $22.1 \pm 0.56$ & $21.0 \pm 0.72$ & $24.0 \pm 0.70$ & $27.0 \pm 0.84$ & $30.2 \pm 0.42$ & $31.0 \pm 0.76$ \\
\hline & $\mathbf{M}_{2}$ & $65.3 \pm 0.64$ & $71.0 \pm 0.72$ & $73.0 \pm 0.79$ & $71.4 \pm 0.69$ & $73.0 \pm 0.42$ & $72.0 \pm 0.95$ & $74.0 \pm 0.78$ & $74.5 \pm 0.76$ \\
\hline & $\mathbf{M}_{3}$ & $69.3 \pm 0.57$ & $71.4 \pm 0.56$ & $72.0 \pm 0.59$ & $70.2 \pm 0.59$ & $71.2 \pm 0.93$ & $73.0 \pm 0.64$ & $71.2 \pm 0.67$ & $72.5 \pm 0.90$ \\
\hline & $\mathbf{K}_{1}$ & $35.1 \pm 0.72$ & $45.0 \pm 0.61$ & $44.5 \pm 0.84$ & $48.0 \pm 0.29$ & $48.3 \pm 0.49$ & $52.2 \pm 0.45$ & $57.0 \pm 0.61$ & $57.1 \pm 0.44$ \\
\hline & $\mathbf{K}_{2}$ & $49.0 \pm 0.58$ & $60.4 \pm 0.51$ & $61.2 \pm 0.41$ & $64.3 \pm 0.38$ & $65.3 \pm 0.58$ & $66.3 \pm 0.93$ & $65.7 \pm 0.59$ & $66.0 \pm 0.41$ \\
\hline & $\mathbf{K}_{3}$ & $60.4 \pm 0.76$ & $63.0 \pm 0.66$ & $62.1 \pm 0.92$ & $63.1 \pm 0.72$ & $63.3 \pm 0.76$ & $66.1 \pm 0.64$ & $67.0 \pm 0.64$ & $66.3 \pm 0.84$ \\
\hline & $\mathbf{P}_{1}$ & $16.3 \pm 0.56$ & $16.7 \pm 0.75$ & $18.0 \pm 0.47$ & $23.5 \pm 0.74$ & $26.5 \pm 0.72$ & $27.4 \pm 0.49$ & $28.8 \pm 0.64$ & $29.0 \pm 0.55$ \\
\hline & $\mathbf{P}_{2}$ & $22.3 \pm 0.51$ & $27.8 \pm 0.81$ & $28.6 \pm 0.70$ & $30.2 \pm 0.80$ & $32.7 \pm 0.47$ & $33.3 \pm 0.76$ & $33.9 \pm 0.58$ & $34.3 \pm 0.46$ \\
\hline & $\mathbf{P}_{3}$ & $27.6 \pm 0.71$ & $31.8 \pm 0.41$ & $32.2 \pm 0.43$ & $32.7 \pm 0.60$ & $36.7 \pm 0.70$ & $37.1 \pm 0.64$ & $37.8 \pm 0.99$ & $38.4 \pm 0.64$ \\
\hline
\end{tabular}
dispersibility and particle size reduction (EI-Badry et al.,

TABLE II - Drug release pattern of various formulations

Each value is a Mean \pm SE of three determination. 
2013). Furthermore, Solvent method produces a uniform distribution of drug in the copolymer carrier crust in highly dispersed state. Thus, when such system becomes in contact with dissolution medium, the hydrophilic carrier dissolves rapidly. In addition, the Poloxamer-188 has surface activity so it reduces the interfacial tension between the solid dispersion and dissolution medium and decreases the aggregation of drug particles and enhances the dissolution rate of drug. The dissolution of the physical mixtures was higher compared to pure CA.

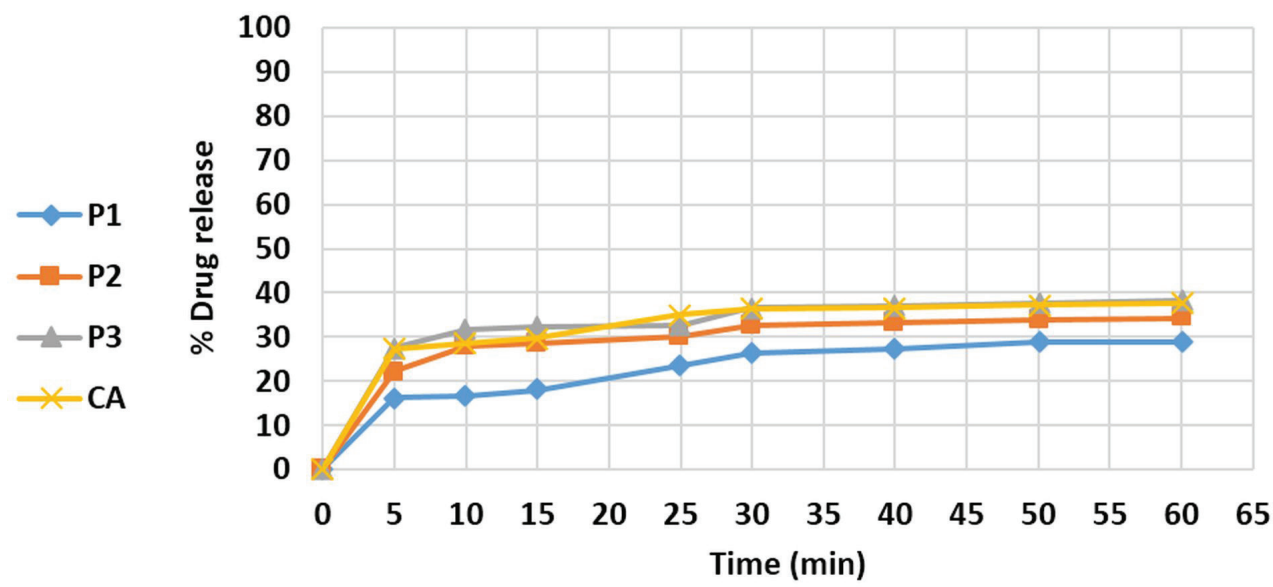

FIGURE 2 - In vitro dissolution profiles of cefuroxime axetil and physical mixtures.

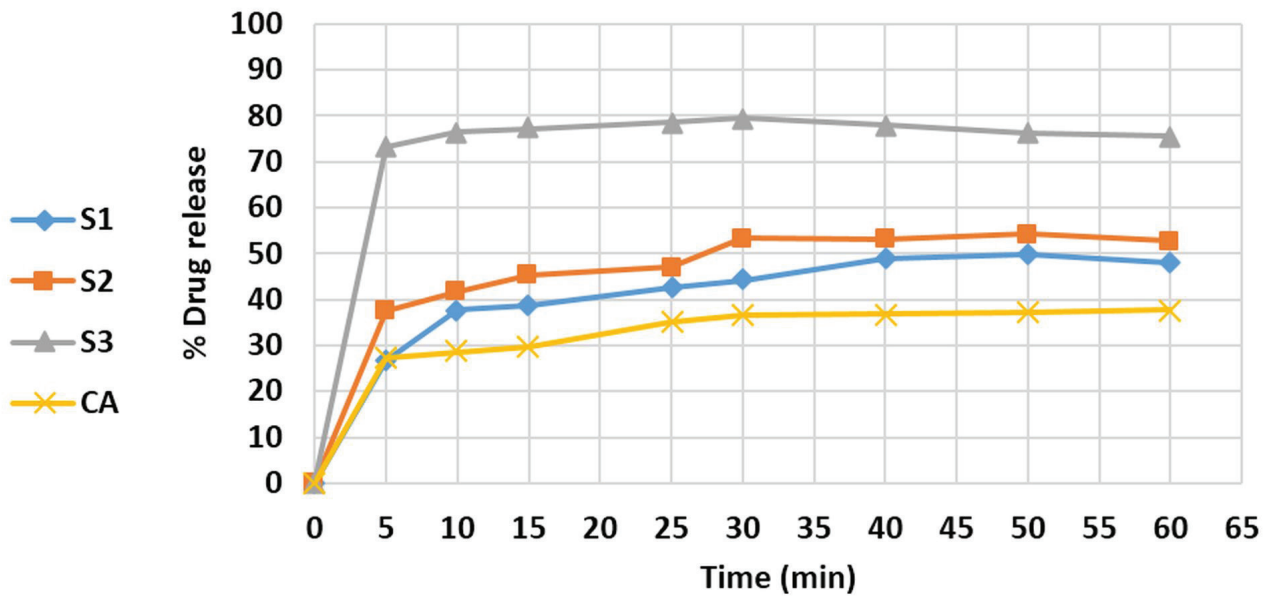

FIGURE 3 - In vitro dissolution profiles of cefuroxime axetil and solid dispersions prepared by solvent method.

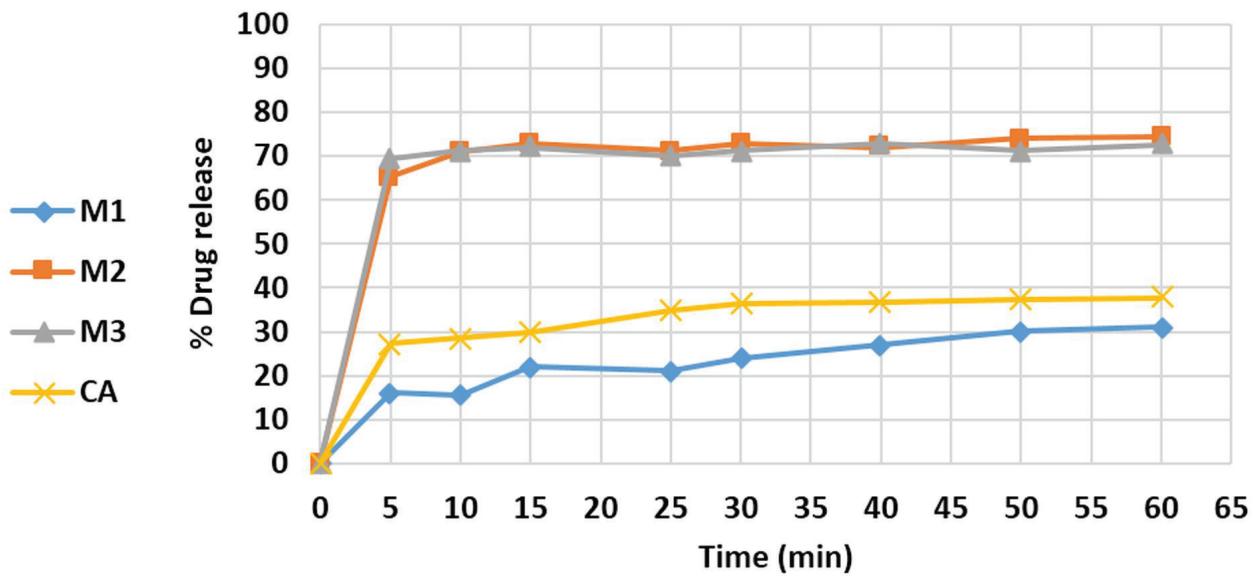

FIGURE 4 - In vitro dissolution profiles of cefuroxime axetil and solid dispersions prepared by melt evaporation method. 


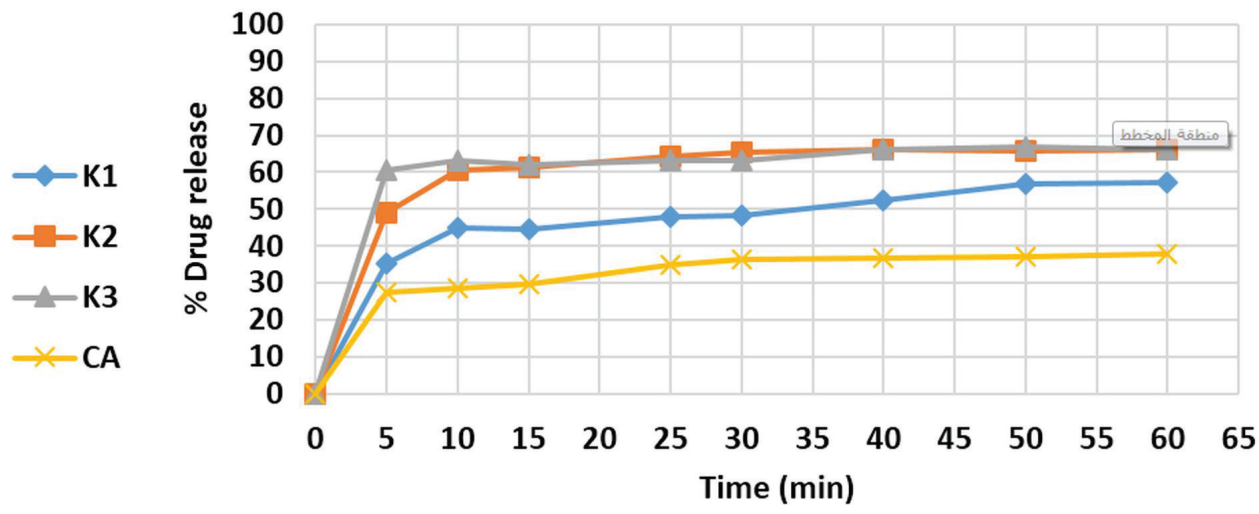

FIGURE 5 - In vitro dissolution profiles of cefuroxime axetil and solid dispersions prepared by kneading method.

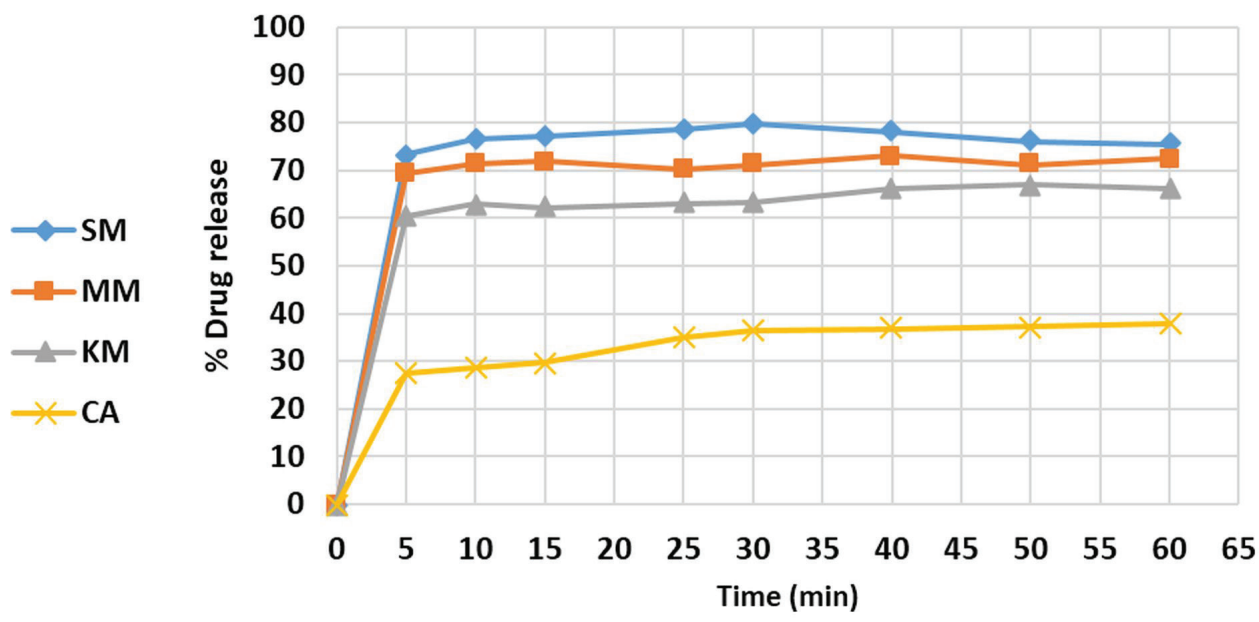

FIGURE 6 - Comparative in vitro dissolution profiles of solid dispersions (1:3) prepared by three methods with pure drug.

SDs of CA in hydrophilic carrier considerably enhanced dissolution compared to the physical mixtures. (Jafar, Mhg and Shareef 2010) study showed the solid dispersions of Meloxicam with PEG 6000 improved dissolution when compared with physical mixtures and pure drug.

\section{Drug content}

The drug content was found in the range of $90.6 \pm 1.14$ to $95.7 \pm 0.91$ indicating the acceptability of method for preparation of solid dispersions. drug content of the prepared solid dispersions has been shown in Table III.

\section{Standard curve}

The drug evaluated for formulation before their formulation. Standard Calibration Curve of Cefuroxime Axetil was prepared in phosphate buffer ( $\mathrm{pH}$ 6.8) at $\lambda$ max $280 \mathrm{~nm}$ (Table IV). The standard curve of cefuroxime axetil produced is as shown in (Figure 7) (Pande, Biyani, 2017).
TABLE III - Drug content of the various solid dispersions prepared

\begin{tabular}{cc}
\hline Formulation code & Drug content \% \\
\hline $\mathrm{S}_{1}$ & $91.3 \pm 1.40$ \\
$\mathrm{~S}_{2}$ & $90.6 \pm 1.14$ \\
$\mathrm{~S}_{3}$ & $90.9 \pm 0.93$ \\
$\mathrm{M}_{1}$ & $92.4 \pm 1.04$ \\
$\mathrm{M}_{2}$ & $91.2 \pm 0.62$ \\
$\mathrm{M}_{3}$ & $92.2 \pm 0.86$ \\
$\mathrm{~K}_{1}$ & $95.7 \pm 0.98$ \\
$\mathrm{~K}_{2}$ & $94.8 \pm 0.99$ \\
$\mathrm{~K}_{3}$ & $95.7 \pm 0.91$ \\
\hline
\end{tabular}

Each value is a Mean $\pm \mathrm{SE}$ of three determination.

\section{Solubility study}

The solubility studies of CA and its various formulations are shown in Table $\mathrm{V}$. all formulations of SD had statistical significantly better solubility compared 


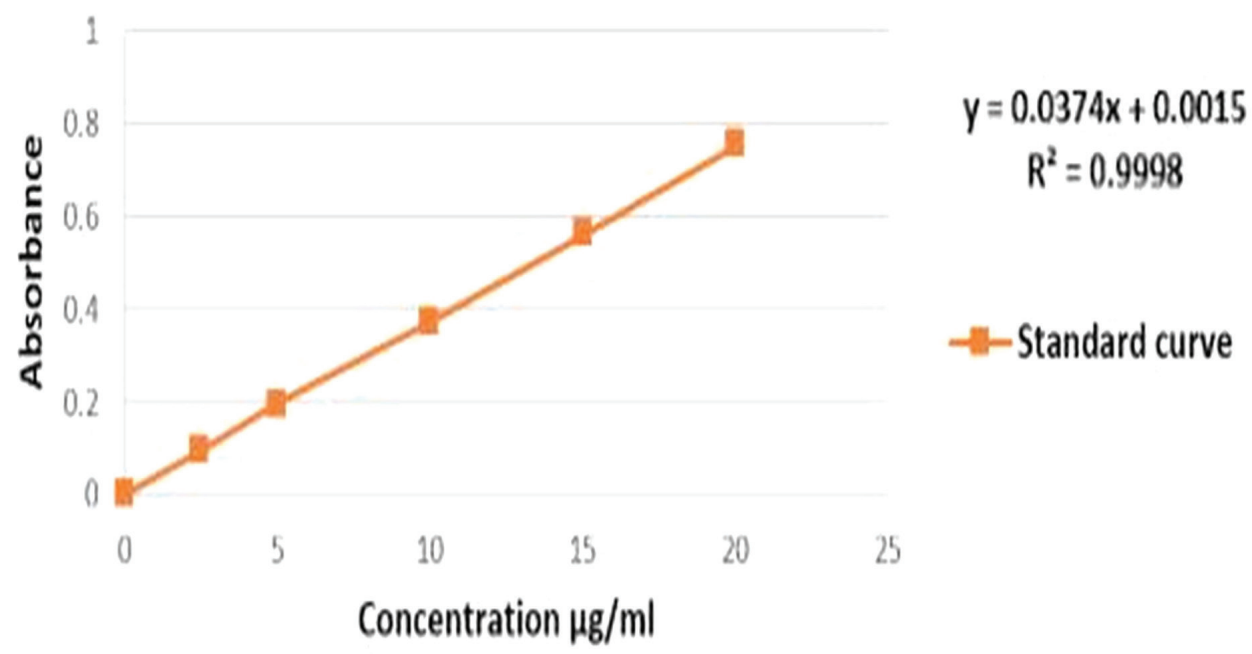

FIGURE 7 - Standard curve of cefuroxime axetil in phosphate buffer (pH 6.8).

TABLE IV - Standard Calibration curve of cefuroxime axetil

\begin{tabular}{cc}
\hline Concentration $(\boldsymbol{\mu g} / \mathbf{m L})$ & Absorbance $(\mathbf{n m})$ \\
\hline 2.5 & $0.094 \pm 0.009$ \\
5 & $0.195 \pm 0.006$ \\
10 & $0.372 \pm 0.004$ \\
15 & $0.560 \pm 0.004$ \\
20 & $0.752 \pm 0.003$ \\
\hline
\end{tabular}

Each value is a Mean $\pm \mathrm{SE}$ of three determination.

with pure CA. The increase in solubility with increasing poloxamer concentration indicates the solvent properties of poloxamer 188 for the drug. Poloxamer 188 causes a decrease of interfacial tension between the drug and solubility medium. These results could be explained that the reduction in crystallinity of drug led to a decrease of

TABLE V - Solubility of CA and its formulations

\begin{tabular}{cc}
\hline Formulation code & Solubility \% \\
\hline $\mathrm{CA}$ & $39.1 \pm 0.97$ \\
$\mathrm{~S}_{1}$ & $77.2 \pm 0.97$ \\
$\mathrm{~S}_{2}$ & $60.7 \pm 0.81$ \\
$\mathrm{~S}_{3}$ & $66.7 \pm 0.91$ \\
$\mathrm{M}_{1}$ & $68.8 \pm 0.67$ \\
$\mathrm{M}_{2}$ & $78.8 \pm 0.84$ \\
$\mathrm{M}_{3}$ & $64.3 \pm 0.84$ \\
$\mathrm{~K}_{1}$ & $53.6 \pm 0.88$ \\
$\mathrm{~K}_{2}$ & $59.3 \pm 0.74$ \\
$\mathrm{~K}_{3}$ & $64.3 \pm 0.66$ \\
\hline
\end{tabular}

Each value is a Mean $\pm \mathrm{SE}$ of three determination. the energy required in the dissolving process and also to a highly dispersed state of the drug (Prasanthi et al., 2011).

\section{FTIR analysis}

FTIR spectroscopy analysis was done to analyze physico-chemical interactions between cefuroxime axetil and poloxamer 188 in form of solid dispersions. (Figure 8 ) represents the FTIR spectra and characteristic wave numbers of cefuroxime axetil and poloxamer 188. The IR spectrum of CA shows two carbonyl absorption bands at $1677.25 \mathrm{~cm}^{-1}$, assigned to amide carbonyl stretching. There were two absorption peak at 3474.47 and $1778 \mathrm{~cm}^{-1}$, assigned to secondary $\mathrm{N}-\mathrm{H}$ stretching vibration and $\mathrm{a} \mathrm{C}=\mathrm{O}$ stretching of vinyl ester. Poloxamer 188 spectrum showed characteristic peaks at $3447.94,2883.23$, and $1101.81 \mathrm{~cm}^{-1}$ due to stretching of $\mathrm{O}-\mathrm{H}, \mathrm{C}-\mathrm{H}$, and $\mathrm{C}-\mathrm{O}$ groups.

In the spectra of all physical mixture and SD formulations, major characteristic peaks of both drug individually and polymer were retained. We expect that there was no chemical interactions amongst the components of the formulation and compatibility of the drug with the carrier (Arora et al., 2010; Dua et al., 2011). The study indicates that CA Probability has strong physical interaction with poloxamer 188 in solid state. FTIR spectroscopy revealed the possibility of inter-molecular hydrogen bonding in solid dispersions (Jun et al., 2005; Sharma, Jain, Tanwar, 2013).

\section{Differential scanning calorimetry (DSC) analysis}

Differential scanning calorimetry (DSC) is frequently used in the pharmaceutical field as a thermal analysis technique, to provide detailed information about both the 


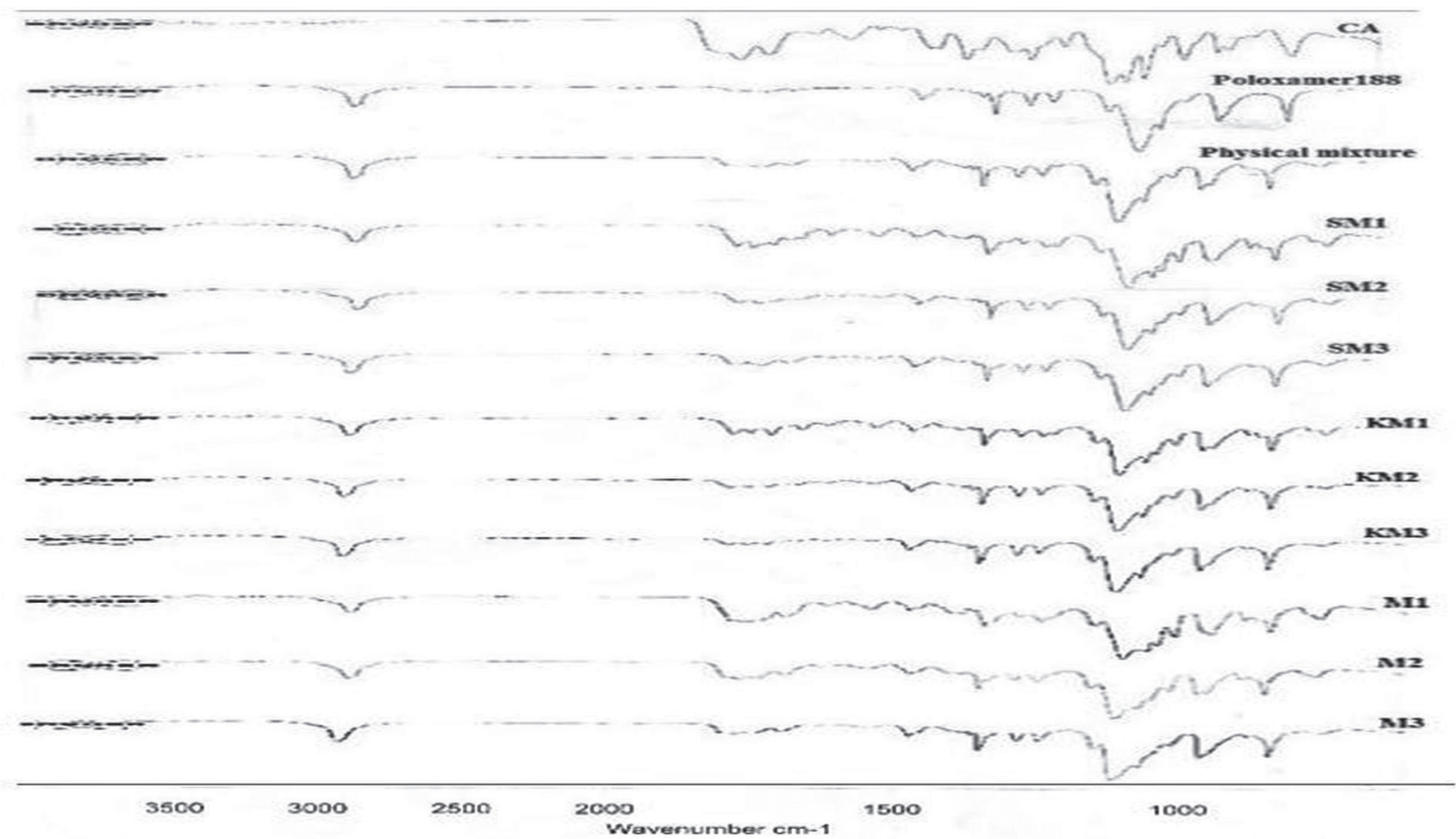

FIGURE 8 - IR spectrum of cefuroxime axetil, poloxamer 188, and their formulations.

physical and energetic properties of substances (EI-Badry et al., 2013). (Figure 9) represents the DSC thermograms of CA, poloxamer 188 and SDs of CA (formulation $\mathrm{S}_{3}, \mathrm{M}_{3}$ and $\mathrm{K}_{3}$ ). In the thermogram of poloxamer 188 , a sharp peak $\left(54.18^{\circ} \mathrm{C}\right)$ was observed, which was associated with the endothermic melting of poloxamer 188 . Whereas, the DSC thermogram of CA exhibited a sharp endothermic peak at $86.36^{\circ}$ and $179.56^{\circ}$ and exothermic peak at $217.69^{\circ}$. The position of the melting peak of poloxamer 188 remained largely unchanged, while that of CA shifted depending on the concentration of polymer. At a ratio of (1:3), the endothermic peak of CA was no longer observed. This

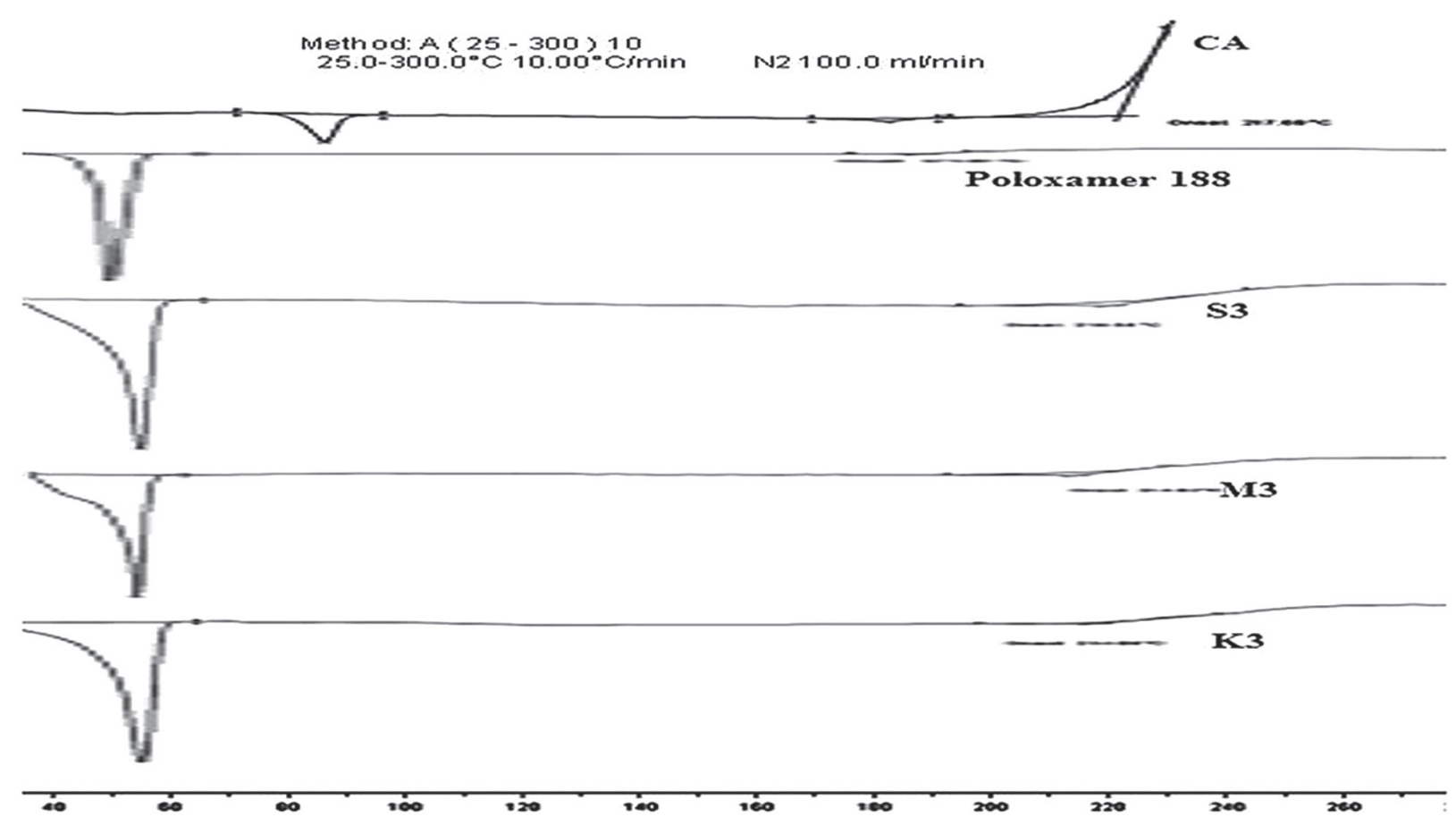

FIGURE 9 - Differential scanning calorimetric thermograms of cefuroxime axetil, poloxamer 188, and their formulations. 
could be because CA was molecularly or amorphously dispersed in the phases (Liu et al., 2006). It is worthy to note that the DSC Studies indicate that CA has been transformed to an amorphous or less crystalline form in its-polymer SD systems.

\section{Kinetic analysis of drug release}

The release data were fitted to various kinetic models in order to calculate the release constant and regression coefficients $\left(\mathrm{R}^{2}\right)$ as seen in Table VI. A higher correlation, as indicated by $\mathrm{R}^{2}$ was observed for the Higuchi matrix release kinetics in all the selected formulations suggesting the diffusion as a probable prominent mechanism of drug release. In diffusion, the rate of dissolution of drug particles within the matrix must be much faster than that of the diffusion rate of drug leaving the matrix (Gorajana et al., 2015; Joshi, Bolmal, Dandagi, 2014).

\section{Evaluation of powder blends and tablets}

In order to obtain optimum flow characteristics of powder, blends of each formulations $\left(\mathrm{S}_{3}, \mathrm{M}_{3}, \mathrm{~K}_{3}\right)$ were evaluated for bulk density, tapped density, compressibility index and Hausner's ratio as shown in Table VII. The results indicated that all powder blends showed excellent flow characteristics according to BP 2009; ranged from $3.77 \%-7.69 \%$ for Carr's index, and $1.04-1.08$ for Hausner's ratio. Excellent flow of the blends might be due to appropriate composition of poloxamer 188 in all formulations (Israr et al., 2014).

\section{CONCLUSION}

In this paper, an increased solubility and dissolution rate of cefuroxime axetil were achieved by forming a solid dispersion using poloxamer 188 as a carrier. Solid dispersions demonstrated a higher dissolution rate than physical mixtures and pure drug. The enhancement of dissolution rate may be caused by increase wettability,
TABLE VI - Release kinetics data of CA and its formulations

\begin{tabular}{cccc}
\hline Sample & $\begin{array}{c}\text { Zero Order } \\
\left(\mathbf{R}^{\mathbf{2}}\right)\end{array}$ & $\begin{array}{c}\text { First Order } \\
\mathbf{( \mathbf { R } ^ { 2 } )}\end{array}$ & $\begin{array}{c}\text { Higuchi } \\
\mathbf{( \mathbf { R } ^ { 2 } )}\end{array}$ \\
\hline S1 & 0.5949 & 0.6770 & 0.8457 \\
S2 & 0.5033 & 0.5936 & 0.7707 \\
S3 & 0.2303 & 0.2340 & 0.4901 \\
M1 & 0.7625 & 0.8100 & 0.9286 \\
M2 & 0.2935 & 0.3599 & 0.5584 \\
M3 & 0.2456 & 0.2676 & 0.4996 \\
K1 & 0.5722 & 0.6916 & 0.8175 \\
K2 & 0.3898 & 0.4796 & 0.6695 \\
K3 & 0.3049 & 0.3686 & 0.5648 \\
P1 & 0.7268 & 0.7700 & 0.9220 \\
P2 & 0.5176 & 0.5680 & 0.7836 \\
P3 & 0.4777 & 0.5345 & 0.7418 \\
\hline
\end{tabular}

dispersibility reduction in particle size or the formation of CA $\beta$ crystalline. The FT-IR study probability revealed that there was no chemical interaction between drug and poloxamer 188 . Solubility studies showed a solubilizing effect of poloxamer 188 on cefuroxime axetil. The solid dispersion technique used in our study involves relatively simple preparation steps and can be used for preparing granules, tablets and capsules.

\section{ACKNOWLEDGMENTS}

The authors are grateful to Diamond Pharma Pharmaceutical Company especially Mr. Hashem AlAani for gifting the pure cefuroxime axetil and poloxamer 188. We are also thankful the quality control team in Avenzor Pharmaceutical Company especially Ms. Souha Arabi- Katibi and Mr. Eyad Al- Salem for the support. Most of these researches were made at the quality control department of Avenzor Pharmaceutical Company.

TABLE VII - Micromeritic properties of cefuroxime axetil solid dispersions

\begin{tabular}{|c|c|c|c|c|c|c|c|}
\hline Sample & $\begin{array}{c}\text { Mass } \\
(\mathrm{g})\end{array}$ & $\begin{array}{c}\text { Bulk } \\
\text { Volume } \\
\text { (mL) }\end{array}$ & $\begin{array}{c}\text { Tapped } \\
\text { Volume } \\
(\mathrm{mL})\end{array}$ & $\begin{array}{c}\text { Bulk } \\
\text { Density } \\
\text { (g/mL) }\end{array}$ & $\begin{array}{l}\text { Tapped } \\
\text { Density } \\
(\mathrm{g} / \mathrm{mL})\end{array}$ & $\begin{array}{c}\text { Compressibility } \\
\text { Index } \\
(\%)\end{array}$ & $\begin{array}{c}\text { Hausner } \\
\text { Ratio }\end{array}$ \\
\hline $\mathrm{S}_{3}$ & 2.53 & 5.20 & 4.90 & 0.4865 & 0.5163 & 5.77 & 1.06 \\
\hline $\mathbf{M}_{3}$ & 2.82 & 5.30 & 5.10 & 0.5321 & 0.5529 & 3.77 & 1.04 \\
\hline $\mathbf{K}_{3}$ & 2.89 & 6.50 & 6.0 & 0.4446 & 0.4817 & 7.69 & 1.08 \\
\hline
\end{tabular}




\section{REFERENCES}

Arora SC, Sharma PK, Irchhaiya R, Khatkar A, Singh N, Gagoria J. Development, characterization and solubility study of solid dispersion of cefuroxime axetil by solvent evaporation method. J Adv Pharm Technol Res. 2010:1(3):326-329.

British Pharmacopoeia. The British Pharmacopoeia Secretariat of the Medicines and Healthcare products Regulatory Agency, UK; 2009.

Chaulang G, Patil K, Ghodke D, Khan S, Yeole P. Preparation and Characterization of Solid Dispersion Tablet of Furosemide with Crospovidone. Res J Pharm Tech. 2008;1(4):386-389.

Datta M, Kaur M. In vitro release of sodium diclofenac from poloxamer 188 modified montmorillonite as an oral drug delivery vehicle. Int J Pharm Pharm Sci. 2014;6(5):100-110.

Dellamonica P. Cefuroxime axetil. Int J Antimicrob Agents. 1994;4(1):23-36.

Dua K, Pabreja K, Ramana MV, Lather V. Dissolution behavior of $\beta$-cyclodextrin molecular inclusion complexes of aceclofenac. J Pharm Bioallied Sci. 2011;3(3):417-425.

EI-Badry M, Hassan MA, Ibrahim MA, El-Saghir H. Performance of poloxamer 407 as hydrophilic carrier on the binary mixtures with nimesulide. Farmacia. 2013; 61(6):1137.

Gorajana A, Rajendran A, Yew L, Dua K. Preparation and characterization of cefuroxime axetil solid dispersions using hydrophilic carriers. Int J Pharm Invest. 2015;5(3):171-178.

Israr F, Mahmood Z, Hassan F, Hasan S, Jabeen S, Naz S, Bashir L. Formulation design and evaluation of Cefuroxime axetil 125 $\mathrm{mg}$ immediate release tablets using different concentration of sodium lauryl sulphate as solubility enhancer. Braz J Pharm Sci. 2014;50(4):943-953.

Jafar M, Mhg D, Shareef A. Enhancement of dissolution and anti-inflammatory effect of meloxicam using solid dispersions. Int J Appl Pharm. 2010;2(1):22-27.

Jithendra K, Sudhir M, Prasad A, Saradhi A, Reddy E. Dissolution profile enhancement of poorly-water soluble drug midazolam by using solid dispersion technique. Panacea $\mathbf{J}$ Pharm Pharm Sci. 2013;1:5-10.

Joshi M, Bolmal U, Dandagi P. Formulation and evaluation of cefuroxime axetil sol gel for periodontits. Int J Pharm Pharm Sci. 2014;6(7):498-503.
Jun SW, Kim MS, Jo GH, Lee S, Woo JS, Park JS, Hwang SJ. Cefuroxime axetil solid dispersions prepared using solution enhanced dispersion by supercritical fluids. J Pharm Pharmacol. 2005;57(12):1529-1537.

Liu D, Fei X, Wang S, Jiang T, Su D. Increasing solubility and dissolution rate of drugs via eutectic mixtures: itraconazolepoloxamer188 system. Asian J Pharm Sci. 2006;1(3-4):213-221.

Nokhodchi A, Talari R, Valizadeh H, Jalali MB. An investigation on the solid dispersions of chlordiazepoxide. Int J Biomed Sci. 2007;3(3):211-216.

Pande SV, Biyani KR. Dissolution enhancement of BCS Class 4 dssrugs using quality by design approach with solid dispersion technique. Int J Pharm Sci Invention. 2017;(6)1:21- 37

Prasanthi NL, Manikiran SS, Sowmya S, Anusha B, Rama RN. Effect of poloxamer 188 on in vitro dissolution properties of antipsychotic solid dispersions. IJPSRR. 2011;10(1):15-19.

Pichichero ME. Use of selected cephalosporins in penicillin-allergic patients. Diagn Microbiol Infect Disease. 2007;57(3):13S-18S.

Razvi N, Siddiqui S, Khan L. The effect of surfactant on the dissolution rate of ibuprofen tablets. Int Chern Pharm Med J. 2005;2(1):213-216.

Reddy N, Reddy A, Srinivasan S, Kavitha K, Kumar R, Singh $\mathrm{J}$, et al. Better solubility enhancement of poorly water soluble drugs. Int J Inv Pharm Sci. 2013;1(4):267-273.

Reddy RK, Khalil SA, Gouda MW. Effect of dioctyl sodium sulfosuccinate and poloxamer 188 on dissolution and intestinal absorption of sulfadiazine and sulfisoxazole in rats. J Pharm Sci. 1976;65(1):115- 118.

Sharma A, Jain CP, Tanwar YS. Preparation and characterization of solid dispersions of carvedilol with poloxamer 188. J Chil Chem Soc. 2013; 85(1):1553-1557.

Sruti J, Patra CN, Swain SK, Beg S, Palatasingh HR, Dinda $\mathrm{SC}$, Bhanoji ME, et al. Improvement in Dissolution Rate of Cefuroxime Axetil by using Poloxamer 188 and Neusilin US2. Indian J Pharm Sci. 2013;75(1):67- 75.

Vinod J, Chenthilnathan A. Formulation development and evaluation of taste masked Cefuroxime axetil dry suspension. Der Pharm Sinica. 2013;4(2):98-103.

Received for publication on $05^{\text {th }}$ October 2017 Accepted for publication on $06^{\text {th }}$ April 2018 